\title{
Volumetric and three-dimensional examination of sella turcica by cone-beam computed tomography: reference data for guidance to pathologic pituitary morphology
}

\author{
L. Taner ${ }^{1}$, F. Deniz Uzuner ${ }^{1}$, O. Demirel' ${ }^{2}$, K. Güngor ${ }^{2}$ \\ ${ }^{1}$ Department of Orthodontics, Faculty of Dentistry, Gazi University, Ankara, Turkey \\ 2Department of Oral and Dentomaxillofacial Radiology, Faculty of Dentistry, Gazi University, Ankara, Turkey \\ [Received: 8 October 2018; Accepted: 4 November 2018]
}

Background: The aim of the study was to assess the dimensions and volume of sella turcica in healthy Caucasian adults with normal occlusion and facial appearance from cone-beam computed tomography (CBCT) images.

Materials and methods: CBCT images of 80 Caucasian adult patients $(40$ males, 40 females) with normal facial appearance and occlusion taken previously for diagnostic purposes were evaluated. Two groups were constructed in accordance to gender. The volume, length, diameter, and depth of the sella turcica were measured by Romexis software programme. Mann-Whitney $U$ test and Independent t-tests were used for statistical analysis.

Results: The mean lengths of the sella were $9.9 \mathrm{~mm}$ and $10.2 \mathrm{~mm}$, depths were $9.2 \mathrm{~mm}$ and $8.8 \mathrm{~mm}$ and diameters were $12.3 \mathrm{~mm}$ and $12.1 \mathrm{~mm}$ in female and male groups, respectively. Between the genders, no statistically significant differences were found for any of the measurements. There were significantly higher values for the volume of sella turcica in males than in females $\left(1102 \pm 285.3 \mathrm{~mm}^{3}\right.$ and $951.3 \pm 278.5 \mathrm{~mm}^{3}$, respectively).

Conclusions: The dimensions of sella turcica in healthy Caucasian adults with normal occlusion and facial appearance revealed nonsignificant differences between the genders. Individual variability in dimensions and gender differences in the volume are of importance in comparison of patients with craniofacial syndromes and aberrations. Knowledge concerning the dimensions and volume of sella turcica will be clinically relevant for a guidance to consciously realize pituitary disorders. (Folia Morphol 2019; 78, 3: 517-523)

Key words: sella turcica size, sella turcica volume, Turkish saddle, cone-beam computed tomography, adult, gender differences

\section{INTRODUCTION}

Sella turcica, a superior depression located on the sphenoid bone, is closely related to the pituitary gland. Any deviation in the development of the pituitary gland may affect the size and shape of the sella turcica as well $[16,17]$. So, the morphology - size and shape - of the sella turcica gains importance under some clinical conditions such as type 1 diabetes, Turner syndrome, Sheehan's syndrome (SS), Fragile $\mathrm{X}$ syndrome, Trisomy 21, Kallmann syndrome, neu-

Address for correspondence: Assoc. Prof. F. Deniz Uzuner, Department of Orthodontics, Gazi University Faculty of Dentistry, Biskek Cd. (8.Cd.) 82.Sk. No:4 06510 Emek, Ankara, Turkey, tel: +90 31220340 00, mobile: +90 536 6801315, fax: +90 31222392 26, e-mail: fduzuner@yahoo.com.tr 
rofibromatosis type 1, Meckel-Gruber syndrome and Williams syndrome, etc. [5, 10, 12, 16-18]. Enlarged sella can be an indication of a mass lesion such as a pituitary tumour [4]. It would be precious and beneficial to detect the morphology of the sella turcica to assign possible pathologies and signs of systemic diseases [16]. It is reported that in Turner syndrome the sella turcica is larger and more open cranially than normal, with/without a cleft in the bottom [16]. Patients with acromegaly have an enlarged sella turcica mostly due to a pituitary adenoma [3]. An empty sella is the characteristic aspect on three-dimensional (3D) images in SS. Given that the patients have nonspecific complaints there is a possible delay in diagnosis of SS as $9-27$ years $[10,11,25]$. Additionally, the inadequate training of doctors and their unawareness of the syndrome may be the reason for delay in diagnosis [10].

Modern radiological imaging techniques such as cone-beam computed tomography (CBCT) and magnetic resonance Imaging (MRI) are being routinely used for diagnostic purposes. CBCT is designed especially for use on the craniofacial skeleton providing 3D images of the area under examination with a low effective radiation dose and recommended for applications in diagnosis, treatment planning, and posttreatment evaluation for neurosurgeons, orthodontists, maxillofacial surgeons, etc. [20, 28, 29]. Whereas clinicians, dentists, especially orthodontists, may encounter concomitant findings outside their area of expertness [6, 22, 23]. Similarly, Cha et al. [6] emphasized that the coincidental findings could be observed approximately in $25 \%$ of CBCT images taken for dental purposes or for orthodontics which raises the need for proper diagnostic management when incidental findings are discovered. So as to be aware of such abnormal findings in 3D images, the normal structure with its dimensions and shape has to be well-known.

Although alterations in the morphology of the sella turcica may express systematic or cranial diseases, individual deviations in the shape and dimensions of the sella are also reported in normal subjects $[5,29]$. Therefore, studying the sella turcica morphology in different populations has been considered as helpful in establishing normal standards to distinguish abnormal morphology in various craniofacial syndromes and aberrations $[1,2,15]$.

In previous studies $[1-3,7,15,19]$, generally cephalometric data has been evaluated but given the likelihood of inter-individual variability in the morphology of the sella turcica, more detailed and reliable measurements can be obtained with the 3D images. In the literature there are few studies evaluating the sella morphology by means of CT imaging [24, 26]. Whilst, up to date in the literature considering the use of CBCT imaging in evaluation of the volume of the sella turcica has not been encountered. It is seen that most of the studies include subjects within wide age range, which can lead to bias as regards interpretation of results. For this purpose, in this study, dimensions and volume of the sella turcica in a population of healthy Caucasian adults with normal occlusion and facial appearance were assessed from CBCT images and compared in accordance with genders guiding to establish a range of norm values.

\section{MATERIALS AND METHODS}

Cone-beam computed tomography images and clinical records of 422 adult patients taken previously at Oral and Dentomaxillofacial Radiology Clinic for diagnostic purposes were evaluated. A total of 80 patients between 18 and 45 ages with normal facial appearance and occlusion with no signs of systematic diseases, syndromes, cleft or craniofacial traumas were selected. Patients having dental anomalies, transposition or impacted canines, previous orthognathic treatment were excluded. Two groups were constructed in accordance to gender; males ( $n=40$, mean age of $27.49 \pm 8.96)$ and females $(n=40$, mean age of $26.57 \pm 8.58$ ) were matched in reference to age. This study was approved by the Ethical Committee of the University. In the clinic routine, before obtaining $C B C T$ images all patients were informed that the material may be used for research purposes and their informed consent was taken.

The CBCT images were obtained using a Promax 3D unit (Planmeca, Helsinki, Finland), operating at $84 \mathrm{kVp}, 9-14 \mathrm{~mA}$, with a $0.16 \mathrm{~mm}$ voxel size, exposure time of $12 \mathrm{~s}$ and a field of view of $8 \times 8 \mathrm{~cm}$. The $\mathrm{CBCT}$ images were evaluated by the same experienced investigator blinded for knowledge of gender and analysed with inbuilt software (Planmeca, Romexis viewer 2.9.2.R) on a 24-inch Nvidia Quadro FX 380 screen with $1280 \times 1024$ resolution in a quiet room with subdued ambient lighting. The observer was allowed to manipulate the contrast and brightness features and to use the zoom tool of the software for optimal visualisation. The sagittal, axial, and coronal slices (thickness: $1 \mathrm{~mm}$ ) of CBCT images were used to evaluate the volume (Fig. 1) and linear dimensions 


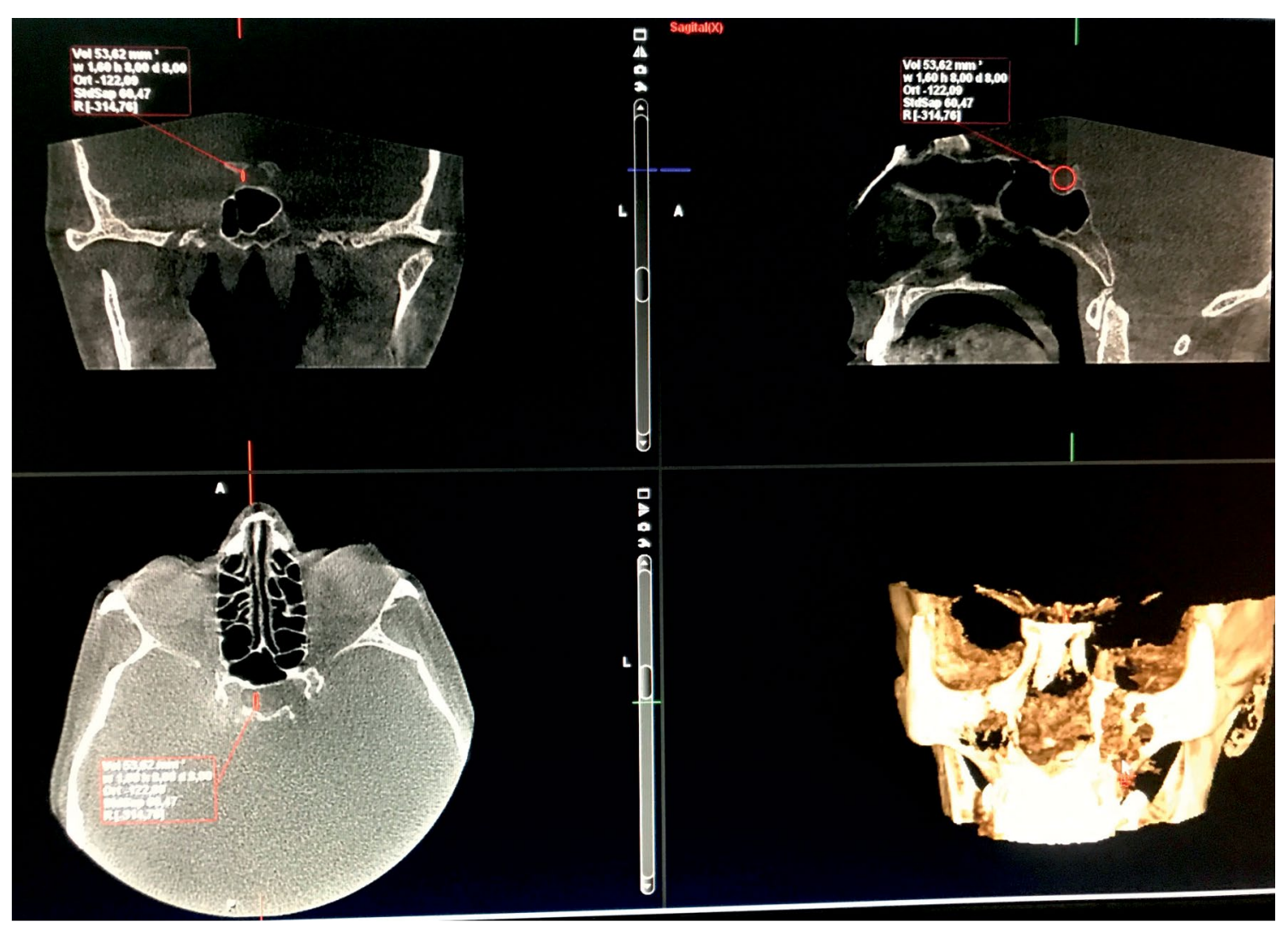

Figure 1. The axial, sagittal and coronal slices of from cone-beam computed tomography images used to evaluate the volume of the sella by Romexis programme ${ }^{\circledR}$ 2.9.2.R.

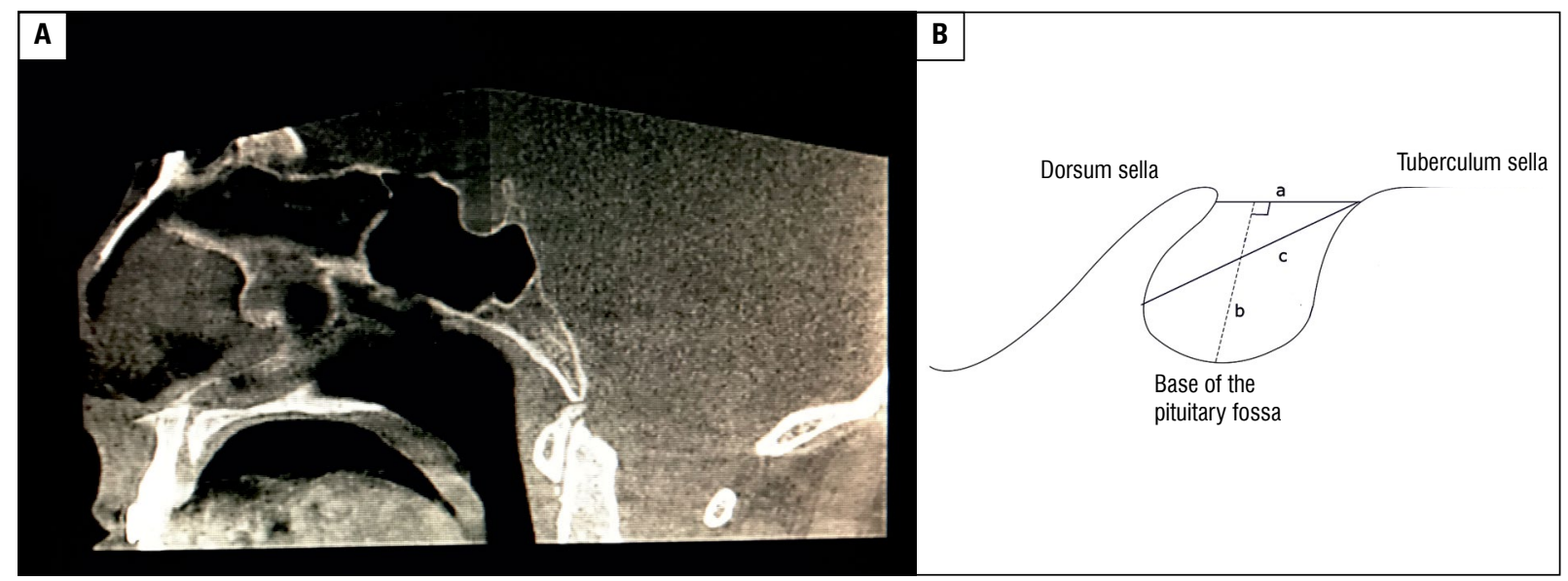

Figure 2. A. Sella turcica cone-beam computed tomography images; B. The anatomic landmarks and the reference lines used for measuring the parameters; tuberculum sellae, the slight anterior elevation on the body of the sphenoid bone. Hypophysial fossa (pituitary fossa), a saddle-like depression for the pituitary gland in the middle, dorsum sellae, which is located posteriorly and is formed by a square plate of bone on the body of the sphenoid, a - length; the distance from the tuberculum sella to the tip of the dorsum sellae, $b$ - depth; a perpendicular from the line above to the deepest point on the floor, c - diameter of the sella; a line also was drawn from the tuberculum sella to the furthest point on the posterior inner wall of the fossa which was considered as the anteroposterior diameter of the sella turcica.

(diameter, depth, and length) of the sella (Figs. 2A, B). In the sagittal slice, a circle most fitting the outer contours of the sella turcica was constructed on the image. Simultaneously, this circle was formed multiplanarly in the axial and coronal slices and the volume was calculated by the Romexis Software programme. 
After an interval of 2 weeks, 20 CBCT images were selected randomly and measurements were repeated. The method error and intra-observer reliability were determined using Dahlberg's formula [8] and paired t-tests.

Power analysis revealed that 40 patients per group at $\alpha=0.05$, yields a statistical power close to $80 \%$ for the present study.

\section{Statistical analysis}

Statistical analysis was made using computer software (SPSS version 20.0, SPSS Inc. Chicago, IL, USA). Data was expressed as mean \pm standard deviation (SD), median and minimum-maximum. The data obtained was submitted to variance homogeneity test by Levene's test and Kolmogorov-Smirnov test was used to determine normality. The parameters that would be analysed using the parametric (independent t-test) and non-parametric (Mann-Whitney U) tests were determined. The level of significance was set at $p<0.05$ for all statistical analyses.

\section{RESULTS}

The method error did not exceed $0.2 \mathrm{~mm}$ for any of the parameters investigated. No significant differences were found between the duplicated measurements $(p>0.05)$.

Dimensions and the volume of the sella turcica according to gender and intergroup comparisons were shown in Table 1.

The mean lengths of the sella were 9.9 and $10.2 \mathrm{~mm}$ in female and male groups, respectively. The mean depths were 9.2 and $8.8 \mathrm{~mm}$ and mean diameters were 12.3 and $12.1 \mathrm{~mm}$ in female and male groups, respectively. Between the genders, no statistically significant differences were found for any of the dimensional parameters. Whereas, there were significantly higher values for volume of sella turcica in males than in females $\left(1102.0 \pm 285.3 \mathrm{~mm}^{3}\right.$ and $951.3 \pm 278.5 \mathrm{~mm}^{3}$, respectively, $\mathrm{p}=0.003$ ).

\section{DISCUSSION}

The development of the radiographic techniques has improved the assessment and differential diagnosis of skull related radiological findings of systemic diseases.

The current study presents data of CBCT images for evaluation of the sella turcica morphology in adult subjects providing complementary input in the literature and emphasizes the utility of CBCT imaging in craniofacial diagnostics enabling assessment of 3D images of
Table 1. Dimensions and volume of the sella turcica according to gender and statistical comparisons

\begin{tabular}{|c|c|c|}
\hline & \multicolumn{2}{|c|}{ Present-day specimens ( $\mathrm{n}=\mathbf{8 0}$ ) } \\
\hline \multicolumn{3}{|l|}{ Gender: } \\
\hline Female (n) & \multicolumn{2}{|c|}{40} \\
\hline Male (n) & \multicolumn{2}{|c|}{40} \\
\hline $\begin{array}{l}\text { Dimensions of the } \\
\text { sella turcica }\end{array}$ & Mean \pm SD & $\begin{array}{c}\text { Median } \\
\text { (minimum-maximum) }\end{array}$ \\
\hline \multicolumn{3}{|l|}{ Length [mm] } \\
\hline Total & $10.0 \pm 1.7$ & $10(6.4-15.3)$ \\
\hline Female & $9.9 \pm 1.9$ & $9.8(6.4-15.3)$ \\
\hline Male & $10.2 \pm 1.6$ & $10.4(7.6-13.2)$ \\
\hline$P$ & \multicolumn{2}{|c|}{$0.413^{*}$} \\
\hline \multicolumn{3}{|l|}{ Depth [mm] } \\
\hline Total & $9.0 \pm 1.5$ & $8.8(6.1-16.7)$ \\
\hline Female & $9.2 \pm 1.7$ & $9.2(6.8-16.7)$ \\
\hline Male & $8.8 \pm 1.4$ & $8.8(6.1-11.7)$ \\
\hline$P$ & \multicolumn{2}{|c|}{$0.236^{* *}$} \\
\hline \multicolumn{3}{|l|}{ Diameter [mm] } \\
\hline Total & $12.2 \pm 2.0$ & $11.9(2.5-17.8)$ \\
\hline Female & $12.3 \pm 1.8$ & $11.8(9.7-17.8)$ \\
\hline Male & $12.1 \pm 2.2$ & $12.3(2.5-15.4)$ \\
\hline$P$ & \multicolumn{2}{|c|}{$0.851^{* *}$} \\
\hline \multicolumn{3}{|l|}{ Volume $\left[\mathrm{mm}^{3}\right]$} \\
\hline Total & $1026.6 \pm 290.2$ & $963.6(601.6-1812.3)$ \\
\hline Female & $951.3 \pm 278.5$ & $899.0(601.6-1812.3)$ \\
\hline Male & $1102.0 \pm 285.3$ & $1088.9(615.1-1726.5)$ \\
\hline$P$ & \multicolumn{2}{|c|}{$0.003^{* *}$} \\
\hline
\end{tabular}

Data are show as number or mean \pm standard deviation $(\mathrm{SD})$, or median (minimum-maximum); * Independent $t$ test, ${ }^{*}$ Mann-Whitney $\mathrm{U}$ test

the area under examination and establishing normal standards to distinguish abnormal morphology. CBCT images of healthy adults were used for this purpose which had been collected previously for several reasons (for orthodontic treatment, prior to planning of implant angulations and/or occlusal plane constructions, evaluation of stabilisation occlusal splint or periodontal problems, etc.). The patients having cleft lip and palate, impacted canines, dental transposition, and dental anomalies were excluded as authors mentioned association between these features and sellar dimensions or bridging $[13,21,24,27]$. Also, patients with previous history of orthognatic treatment were excluded given that abnormal sella dimensions and bridging were reported in those patients [14]. As there is an increase in dimensions of sella turcica until skeletal maturation [1, 2], only adult patients were included in present study. 
The results of this study revealed significantly higher values for the volume of the sella turcica in males than in females, while no gender influence was noted on length, depth or diameter parameters. These findings of the dimensions were in concomitant with the results of the previous studies that reported no difference between the genders in the diameter, depth and length of sella turcica determined by means of $2 \mathrm{D}$ evaluation from the lateral cephalograms $[1,21,29]$.

The cone-beam assessment of the sella volume in adults is not present in the literature; therefore, it was not possible to compare our results directly. The mean volume values $\left(1026.6 \mathrm{~mm}^{3}\right.$; range 601-1812 $\mathrm{mm}^{3}$ ) of the total sample of this study are higher than that reported by Diri et al. [10] $\left(602.5 \pm 192 \mathrm{~mm}^{3}\right.$; range 308-1040 $\mathrm{mm}^{3}$ ). In their study, 3D volumetric MRI was used to evaluate the pituitary gland and sella turcica volumes for both the control and the SS groups by using the Di Chiro formula [9]: $0.5 \times$ (length) $\times$ (width) $\times$ (depth). The differences in the amount of sella volume between our study and that of the control group in the study of Diri et al. [10] may be contributed to the methodological differences. The measurement of the volume was done by the Romexis viewer 2.9.2.R software in this study while, Diri et al. [10] used a formula.

In literature the measurements and their normal values for the dimensions of sella seem to be conflicting. Wide ranges of values can be seen in the previous studies. On average, the reported values for the length of sella were between 5 and $16 \mathrm{~mm}$ and for height between 4 and $12 \mathrm{~mm}[1,7,30]$. Our results are within these ranges. The varying results in those studies might be due to different compositions of the study groups (age, gender, race, etc.), methodologic differences (radiologic techniques; lateral cephalometric, MRI, and measurement techniques), different landmarks representing the same dimensions, different degrees of magnification and in some studies the gender of the population was not considered which have significant effects on the interpretation of the results as can be seen in this study.

Data on linear dimensions of the sella turcica in a Saudi sample of subjects with different skeletal types (class I, II and III) revealed overall average 10.7 and $11.0 \mathrm{~mm}$ of length, $14.0 \mathrm{~mm}$ and $13.9 \mathrm{~mm}$ of diameter in females and males, respectively, with an average $9.1 \mathrm{~mm}$ of depth in both genders [1]. In class I subjects, average values for diameter, depth, and length of the sella turcica was reported to be $10.7 \mathrm{~mm}, 8.9 \mathrm{~mm}$ and $13.9 \mathrm{~mm}$, respectively, with no gender influence on linear dimensions of the sella turcica [1]. Similarly, in a multicentre retrospective study concerning pre-treatment lateral cephalograms of 400 German adults with skeletal class III $(n=250)$ or class I $(n=150)$ malocclusion, average length, depth, and diameter of the sella turcica were reported to be $10.9 \mathrm{~mm}, 8.2 \mathrm{~mm}$ and $13.0 \mathrm{~mm}$ in overall class I patients [2]. Also, average length was reported as $10.7 \mathrm{~mm}$ and $11.2 \mathrm{~mm}$, depth as $8.1 \mathrm{~mm}$ and $8.3 \mathrm{~mm}$ and diameter as $12.9 \mathrm{~mm}$ and $13.1 \mathrm{~mm}$ in skeletal class I females and males, respectively, with no gender influence on sella turcica dimensions [21]. Accordingly, overall average length $(10.0 \mathrm{~mm})$, depth $(9.0 \mathrm{~mm})$, and diameter $(12.2 \mathrm{~mm})$ of the sella turcica in our adult patients with angle class I relationships seem consistent with those reported in patients with skeletal class I malocclusion. Normative data from a longitudinal study on the cephalometric standards for Norwegians revealed increased sella length in male compared with female subjects between 6 and 21 years of age, with no significant differences in diameters and depths. On average, 8.4 and $8.9 \mathrm{~mm}$ of length, $7.2 \mathrm{~mm}$ and $7.3 \mathrm{~mm}$ of depth, $11.7 \mathrm{~mm}$ and $11.3 \mathrm{~mm}$ of diameter in females and males have been reported, respectively [2].

Slightly higher values were noted for the average length $(9.9 \mathrm{~mm}$ and $10.2 \mathrm{~mm})$, depth $(9.2 \mathrm{~mm}$ and $8.8 \mathrm{~mm})$ and diameter $(12.3 \mathrm{~mm}$ and $12.1 \mathrm{~mm})$ of the sella turcica in our female and male patients, comparable to upper limits of the ranges defined for the sella turcica in vertical depth $(4-16 \mathrm{~mm})$ and anteroposterior diameter (5-16 mm).

On the contrary, the values of depth in this study were smaller than Balos Tuncer et al. [3] due to the difference in the measurement method and construction. They did not consider gender differences in their study and evaluated both males and females in the same pool and assessments were done by means of 2D cephalometric radiographs similar to the other studies.

The limitation of this study was the sample size as a result of the retrospective design. Due to the ethics a prospective construction could not be proceeded.

The results of this study will provide a guide to normal ranges of the sella turcica in healthy adult patients with normal occlusions and drive attention to the awareness of detection of nonsymptomatic diseases related to sella and establishing normal 
standards to distinguish abnormal morphology. Our findings emphasize the utility and reliability of CBCT imaging in craniofacial diagnostics and form a solid basis of reference standards for neurosurgeons, orthodontists, anthropologists, and endocrinologists etc. to become more aware of the pathologic anatomy of sella turcica and be conscious of this specific region.

As recommended, for clinical diagnosis, however, the data should only be interpreted with a full history of clinical signs and symptoms and detailed communications with radiological colleagues and other specialists to comprehensively evaluate possible underlying diseases [6].

\section{CONCLUSIONS}

There were inter-individual variations in dimensions (length, depth, and diameter) of the sella turcica in this sample of selected population. Individual variability in dimensions and gender differences in the volume are of importance in comparison of patients with craniofacial syndromes and aberrations.

Interpretation of varying data on dimensions of sella turcica may be challenging, therefore results should be assessed with caution due to potential presence of ethnic variations between the selected populations of the studies.

\section{REFERENCES}

1. Alkofide EA. The shape and size of the sella turcica in skeletal Class I, Class II, and Class III Saudi subjects. Eur J Orthod. 2007; 29(5): 457-463, doi: 10.1093/ejo/cjm049, indexed in Pubmed: 17693429.

2. Axelsson S, Storhaug K, Kjaer I. Post-natal size and morphology of the sella turcica. Longitudinal cephalometric standards for Norwegians between 6 and 21 years of age. Eur J Orthod. 2004; 26(6): 597-604, doi: 10.1093/ ejo/26.6.597, indexed in Pubmed: 15650069.

3. Balos Tuncer B, Canigur Bavbek N, Ozkan C, et al. Craniofacial and pharyngeal airway morphology in patients with acromegaly. Acta Odontol Scand. 2015; 73(6): 433-440, doi: 10.3109/00016357.2014.979868, indexed in Pubmed: 25543455.

4. Bonneville JF, Cattin F, Dietemann JL. Hypothalamic-pituitary region: computed tomography imaging. Baillieres Clin Endocrinol Metab. 1989; 3(1): 35-71, indexed in Pubmed: 2679524.

5. Canigur Bavbek N, Dincer M. Dimensions and morphologic variations of sella turcica in type 1 diabetic patients. Am J Orthod Dentofacial Orthop. 2014; 145(2): 179-187, doi: 10.1016/j.ajodo.2013.10.011, indexed in Pubmed: 24485732.

6. Cha JY, Mah J, Sinclair P. Incidental findings in the maxillofacial area with 3-dimensional cone-beam imaging. Am J Orthod Dentofacial Orthop. 2007; 132(1): 7-14, doi: 10.1016/j.ajodo.2005.08.041, indexed in Pubmed: 17628245

7. Choi WJ, Hwang EH, Lee SR. The study of shape and size of normal sella turcica in cephalometric radiographs. Korean J Oral Maxillofac Radiol. 2001; 31: 43-49.

8. Dahlberg G. Statistical methods for medical and biological students. NewYork: Interscience Publications. 1940.

9. DI Chiro G, Nelson KB. The volume of the sella turcica. Am J Roentgenol Radium Ther Nucl Med. 1962; 87: 989-1008, indexed in Pubmed: 13885978.

10. Diri H, Tanriverdi F, Karaca Z, et al. Extensive investigation of 114 patients with Sheehan's syndrome: a continuing disorder. Eur J Endocrinol. 2014; 171(3): 311-318, doi: 10.1530/EJE-14-0244, indexed in Pubmed: 24917653.

11. Dökmetaş HS, Kilicli F, Korkmaz S, et al. Characteristic features of 20 patients with Sheehan's syndrome. Gynecol Endocrinol. 2006; 22(5): 279-283, doi: 10.1080/09513590600630504, indexed in Pubmed: 16785150.

12. Friedrich RE, Baumann J, Suling $A$, et al. Sella turcica measurements on lateral cephalograms of patients with neurofibromatosis type 1. GMS Interdiscip Plast Reconstr Surg DGPW. 2017; 6: Doc05, doi: 10.3205/iprs000107, indexed in Pubmed: 28401031.

13. Haji Ghadimi M, Amini F, Hamedi S, et al. Associations among sella turcica bridging, atlas arcuate foramen (ponticulus posticus) development, atlas posterior arch deficiency, and the occurrence of palatally displaced canine impaction. Am J Orthod Dentofacial Orthop. 2017; 151(3): 513-520, doi: 10.1016/j.ajodo.2016.08.024, indexed in Pubmed: 28257736.

14. Jones RM, Faqir A, Millett DT, et al. Bridging and dimensions of sella turcica in subjects treated by surgical-orthodontic means or orthodontics only. Angle Orthod. 2005; 75(5): 714-718, doi: 10.1043/0003-3219(2005)75[714:BADOST]2.0.CO;2, indexed in Pubmed: 16279819.

15. Keleştimur F. Sheehan's syndrome. Pituitary. 2003; 6(4): 181-188, doi: 10.1023/b:pitu.0000023425.20854.8e.

16. Kjær I. Sella turcica morphology and the pituitary gland. A new contribution to craniofacial diagnostics based on histology and neuroradiology. Eur J Orthod. 2015; 37(1): 28 -36, doi: 10.1093/ejo/cjs091, indexed in Pubmed: 23159420.

17. Kjaer KW, Hansen BF, Keeling JW, et al. Malformations of cranial base structures and pituitary gland in prenatal Meckel syndrome. APMIS. 1999; 107(10): 937-944, indexed in Pubmed: 10549591.

18. Kjaer I, Keeling JW, Reintoft I, et al. Pituitary gland and sella turcica in human trisomy 21 fetuses related to axial skeletal development. Am J Med Genet. 1998; 80(5): 494-500, doi: 10.1002/(SICI)1096-8628(19981228)80:5<494::AIDJMG11, indexed in Pubmed: 9880215.

19. Kucia A, Jankowski T, Siewniak M, et al. Sella turcica anomalies on lateral cephalometric radiographs of Polish children. Dentomaxillofac Radiol. 2014; 43(8): 20140165, doi: 10.1259/dmfr.20140165, indexed in Pubmed: 25182120.

20. Mah JK, Huang JC, Choo H. Practical applications of cone-beam computed tomography in orthodontics. J Am Dent Assoc. 2010; 141 Suppl 3: 7S-713S, indexed in Pubmed: 20884934.

21. Meyer-Marcotty P, Reuther T, Stellzig-Eisenhauer A. Bridging of the sella turcica in skeletal Class III subjects. Eur 
J Orthod. 2010; 32(2): 148-153, doi: 10.1093/ejo/cjp081, indexed in Pubmed: 19752019.

22. Miles DA. Clinical experience with cone beam volumetric imaging: a report of findings in 381 cases. US Dent. 2006; 1: 39-41.

23. Newaz ZA, Barghan S, Katkar RA, et al. Incidental findings of skull-base abnormalities in cone-beam computed tomography scans with consultation by maxillofacial radiologists. Am J Orthod Dentofacial Orthop. 2015; 147(1): 127-131, doi: 10.1016/j.ajodo.2014.09.019, indexed in Pubmed: 25533079.

24. Paknahad M, Shahidi S, Khaleghi I. A cone beam computed tomographic evaluation of the size of the sella turcica in patients with cleft lip and palate. J Orthod. 2017; 44(3): 164-168, doi: 10.1080/14653125.2017.1343221, indexed in Pubmed: 28673207.

25. Ramiandrasoa C, Castinetti F, Raingeard I, et al. Delayed diagnosis of Sheehan's syndrome in a developed coun- try: a retrospective cohort study. Eur J Endocrinol. 2013; 169(4): 431-438, doi: 10.1530/EJE-13-0279, indexed in Pubmed: 23864341.

26. Ruiz C, Wafae N, Wafae G. Sella Turcica morphometry using computed tomography. Eur J Anat. 2008; 12: 47-50.

27. Scribante A, Sfondrini MF, Cassani M, et al. Sella turcica bridging and dental anomalies: is there an association? Int J Paediatr Dent. 2017; 27(6): 568-573, doi: 10.1111/ /ipd.12301, indexed in Pubmed: 28387468.

28. Seidenwurm DJ. Neuroendocrine imaging. AJNR Am J Neuroradiol. 2008; 29(3): 613-615, indexed in Pubmed: 18337394.

29. Tekiner H, Acer N, Kelestimur F. Sella turcica: an anatomical, endocrinological, and historical perspective. Pituitary. 2015; 18(4): 575-578, doi: 10.1007/s11102-014-0609-2, indexed in Pubmed: 25307180.

30. Yassir AY, Nahidh M, Yousif HA. Size and morphology of sella turcica in Iraqi adults. Mustansiria Dent J. 2010; 7: 23-30. 